\title{
Hydrogen Back-Pressure Effects on the Dehydrogenation Reactions of $\mathrm{Ca}\left(\mathrm{BH}_{4}\right)_{2}$
}

\author{
Yoonyoung Kim, ${ }^{\dagger}{ }^{\ddagger}$ Son-Jong Hwang, ${ }^{\S}$ Young-Su Lee, ${ }^{\dagger}$ Jin-Yoo Suh, $^{\dagger}$ Heung Nam Han, ${ }^{\ddagger}$
} and Young Whan Cho*, ${ }^{\dagger}$

${ }^{\dagger}$ High Temperature Energy Materials Research Center, Korea Institute of Science and Technology, Seoul 136-791, Republic of Korea
${ }^{\ddagger}$ Department of Materials Science and Engineering, Seoul National University, Seoul 151-742, Republic of Korea
${ }^{\S}$ Division of Chemistry and Chemical Engineering, California Institute of Technology, Pasadena, California 91125, United States

Supporting Information

\begin{abstract}
The dehydrogenation reactions of $\mathrm{Ca}\left(\mathrm{BH}_{4}\right)_{2}$ are investigated under different isobaric conditions using in situ synchrotron radiation powder $\mathrm{X}$-ray diffraction and nuclear magnetic resonance measurements. $\mathrm{Ca}\left(\mathrm{BH}_{4}\right)_{2}$ dissociates in multiple steps, and several intermediate phases, such as an amorphous phase $(\mathrm{s}), \mathrm{CaB}_{2} \mathrm{H}_{x}$, and $\mathrm{CaB}_{12} \mathrm{H}_{12}$, are observed during dehydrogenation. Among the intermediate phases, it is known that $\mathrm{CaB}_{2} \mathrm{H}_{x}$ is fully reversible, while the more stable $\mathrm{CaB}_{12} \mathrm{H}_{12}$ with an icosahedral structure hinders reversible reactions. Here, we try to control the dehydrogenation reaction pathway of $\mathrm{Ca}\left(\mathrm{BH}_{4}\right)_{2}$ by applying different hydrogen backpressures. The decomposition reaction of $\mathrm{Ca}\left(\mathrm{BH}_{4}\right)_{2}$ in the absence of a catalyst was found to be sensitive to the $\mathrm{H}_{2}$ back-

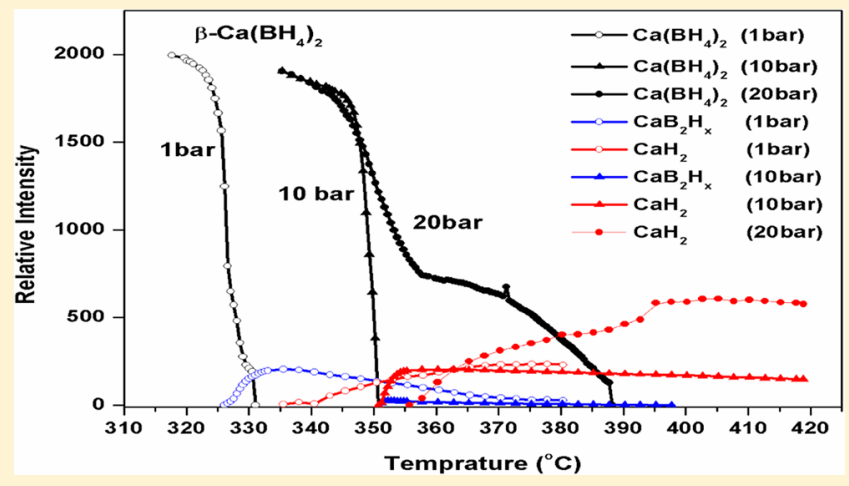
pressure. At $p\left(\mathrm{H}_{2}\right)=1$ bar, $\mathrm{Ca}\left(\mathrm{BH}_{4}\right)_{2}$ decomposes via two competitive dehydrogenation reaction routes to form $\mathrm{CaB}_{2} \mathrm{H}_{x}$ or $\mathrm{CaB}_{12} \mathrm{H}_{12}$. At $p\left(\mathrm{H}_{2}\right)=10$ bar, the overall dehydrogenation reaction remains unchanged. However, the formation of $\mathrm{CaB}_{2} \mathrm{H}_{x}$ is reduced, and amorphous elemental boron is observed as a final dehydrogenation product. At $p\left(\mathrm{H}_{2}\right)=20$ bar, the elemental boron formation is significantly increased, and the formation of the $\mathrm{CaB}_{2} \mathrm{H}_{x}$ phase is suppressed. Possible routes to form $\mathrm{CaH}$ and elemental boron are discussed.
\end{abstract}

\section{INTRODUCTION}

Light metal borohydrides are considered promising materials for solid-state hydrogen storage due to their high hydrogen content. Among the borohydrides, $\mathrm{Ca}\left(\mathrm{BH}_{4}\right)_{2}$ has high gravimetric (11.5 wt \%) and volumetric $\left(130 \mathrm{~kg} / \mathrm{m}^{3}\right)$ hydrogen contents. ${ }^{1}$ In principle, $\mathrm{Ca}\left(\mathrm{BH}_{4}\right)_{2}$ could release a maximum of 9.6 wt \% hydrogen when the following overall decomposition reaction pathway is employed:

$$
\mathrm{Ca}\left(\mathrm{BH}_{4}\right)_{2} \rightarrow{ }^{2} / 3 \mathrm{CaH}_{2}+{ }^{1} / 3 \mathrm{CaB}_{6}+{ }^{10} /{ }_{3} \mathrm{H}_{2}
$$

However, the dehydrogenation of $\mathrm{Ca}\left(\mathrm{BH}_{4}\right)_{2}$ is not a simple one-step reaction. $\mathrm{CaH}_{2}$ has been commonly observed in the final dehydrogenation product, but several intermediate phases, such as $\mathrm{CaB}_{2} \mathrm{H}_{x}{ }^{2-6}$ an unidentified noncrystalline phase(s), , $^{3,7-9}$ and $\mathrm{CaB}_{12} \mathrm{H}_{12}$, ${ }^{3,9,10}$ have been observed during the thermal dehydrogenation of $\mathrm{Ca}\left(\mathrm{BH}_{4}\right)_{2}$. Note that, in the literature, no uniform experimental protocol has been proposed for this complex hydride, so widely different experimental dehydrogenation conditions $\left(\mathrm{H}_{2}\right.$ partial pressures and temperatures) have been investigated. ${ }^{2-10}$ We believe that this is one possible reason why different reaction intermediate phases were observed. The pressure control that most studies have employed in the past is dehydrogenation under dynamic or static vacuum, ${ }^{2,4,11-13}$ which may not be a well-defined or suitable condition.

We investigated the dehydrogenation of $\mathrm{Ca}\left(\mathrm{BH}_{4}\right)_{2}$ under isobaric conditions $\left(p\left(\mathrm{H}_{2}\right)=1\right.$ bar $)$ in our previous study. ${ }^{3}$ While the result was rather complex, it was summarized that the following two reaction routes took place almost simultaneously:

$$
\begin{aligned}
\mathrm{Ca}\left(\mathrm{BH}_{4}\right)_{2} & \rightarrow \text { amorphous phase } \\
& \rightarrow \mathrm{CaB}_{2} \mathrm{H}_{x}+{ }^{(8-x)} /{ }_{2} \mathrm{H}_{2} \\
& \rightarrow 2 /{ }_{3} \mathrm{CaH}_{2}+1 /{ }_{3} \mathrm{CaB}_{6}+10 /{ }_{3} \mathrm{H}_{2} \\
\mathrm{Ca}\left(\mathrm{BH}_{4}\right)_{2} & \rightarrow \text { amorphous phase } \\
& \rightarrow 1 / 6 \mathrm{CaB}_{12} \mathrm{H}_{12}+5 / 6 \mathrm{CaH}_{2}+{ }^{13} /{ }_{6} \mathrm{H}_{2}
\end{aligned}
$$

"Amorphous phase" here should be thought of as an unidentified noncrystalline phase from an X-ray diffraction (XRD) standpoint instead of a definite intermediate phase in the chemical reaction. In our previous ${ }^{11} \mathrm{~B}$ magic-angle spinning

Received: September 10, 2012

Revised: November 19, 2012

Published: November 20, 2012 
(MAS) NMR study, we reported ${ }^{3}$ that the amorphous phase was mainly represented by a broad $\sim-32 \mathrm{ppm}$ peak that most likely originated from residual $\mathrm{Ca}\left(\mathrm{BH}_{4}\right)_{2}$ in noncrystalline form. Another important point here is that the -32 ppm peak was confirmed to not be attributed to possible $\mathrm{Ca}\left(\mathrm{B}_{3} \mathrm{H}_{8}\right)_{2}$ formation from our ${ }^{11} \mathrm{~B}$ solution NMR of water dissolution study of the reaction products. Recently, there has been growing interest in $\mathrm{B}_{3} \mathrm{H}_{8}{ }^{-}$formation ${ }^{14,15}$ because of the identification of $\mathrm{Mg}$ $\left(\mathrm{B}_{3} \mathrm{H}_{8}\right)_{2}$ in $\mathrm{Mg}\left(\mathrm{BH}_{4}\right)_{2}$ thermal decomposition. ${ }^{14}$

The formation of a considerable amount of $\mathrm{CaB}_{12} \mathrm{H}_{12}$ was also observed during dehydrogenation under 1 bar of $\mathrm{H}_{2}$ pressure. The formation of $\mathrm{CaB}_{12} \mathrm{H}_{12}$ is not desirable because of its high thermal stability and should therefore be avoided during dehydrogenation, especially when hydrogen storage application is concerned. In the case of the $\mathrm{LiBH}_{4}+\mathrm{YH}_{3}$ composite, it was demonstrated that the formation of intermediate $\mathrm{Li}_{2} \mathrm{~B}_{12} \mathrm{H}_{12}$ could be suppressed when dehydrogenation occurred under a $\mathrm{H}_{2}$ pressure greater than 3 bar. ${ }^{15,16} \mathrm{~A}$ similar $\mathrm{H}_{2}$ back-pressure effect was also reported for the $\mathrm{LiBH}_{4}$ $+\mathrm{MgH}_{2}$ composite. ${ }^{17,18}$

As shown above, the stability of intermediate compounds could be as important as that of the final products in determining the overall reversibility of the reaction. A systematic study on the effect of the dehydrogenation conditions on the reaction pathway is required. In this study, we explore the dehydrogenation reaction of $\mathrm{Ca}\left(\mathrm{BH}_{4}\right)_{2}$ under four different isobaric conditions $\left(p\left(\mathrm{H}_{2}\right)=1,5,10\right.$, and 20 bar). The primary goal of the present study is to investigate whether the formation of stable dehydrogenated products, such as $\mathrm{CaB}_{12} \mathrm{H}_{12}$ or elemental boron, can be suppressed when $\mathrm{H}_{2}$ back-pressure is applied.

\section{EXPERIMENTAL SECTION}

$\mathrm{Ca}\left(\mathrm{BH}_{4}\right)_{2}$ (Sigma-Aldrich, lot no. $17696 \mathrm{LKV}$ ) was used without any further purification. All samples were handled in an argon-filled glovebox that maintained the $\mathrm{O}_{2}$ and $\mathrm{H}_{2} \mathrm{O}$ levels below 1 ppm.

In situ synchrotron radiation powder X-ray diffraction (SRPXD) measurements were carried out at the 10B XRS KISTPAL beamline in the Pohang Accelerator Laboratory (Pohang, Korea). The selected X-ray wavelength was $1.00001 \AA$, and sapphire capillary tubes with a $1.07 \mathrm{~mm}$ inner diameter were used. Three $\mathrm{Ca}\left(\mathrm{BH}_{4}\right)_{2}$ samples were heated from room temperature to $300{ }^{\circ} \mathrm{C}$ in $30 \mathrm{~min}$ and then heated to $420{ }^{\circ} \mathrm{C}$ at a rate of $0.2^{\circ} \mathrm{C} / \mathrm{min}$. The hydrogen pressure of each sample was maintained at 1,10 , and $20 \mathrm{bar}$, respectively. For ex situ XRD and NMR measurements, approximately $0.1 \mathrm{~g}$ of $\mathrm{Ca}\left(\mathrm{BH}_{4}\right)_{2}$ was heated to the target temperature under the same isobaric conditions $\left(p\left(\mathrm{H}_{2}\right)=1,5,10\right.$, and $\left.20 \mathrm{bar}\right)$ at a ramping rate of $0.2{ }^{\circ} \mathrm{C} / \mathrm{min}$ and then cooled to room temperature in the furnace using a Sievert-type apparatus. The ex situ XRD data were obtained at room temperature using a Bruker D8 Advance powder diffractometer with $\mathrm{Cu} \mathrm{K} \alpha$ radiation (1.5418 $\AA$ ) and a focusing Göbel mirror. The powders were placed into boron silicate capillary tubes with a $0.7 \mathrm{~mm}$ diameter in the glovebox.

Solid-state NMR measurements were performed using a Bruker DSX-500 spectrometer and a boron-free Bruker $4 \mathrm{~mm}$ MAS probe. Samples in powder form were packed into $4 \mathrm{~mm}$ $\mathrm{ZrO}_{2}$ rotors and sealed with tight-fitting kel-F caps inside an Arfilled glovebox. Sample spinning was performed under dry nitrogen gas to avoid exposure to oxygen or moisture. ${ }^{11} \mathrm{~B}$ MAS NMR spectra were recorded after a short $\pi / 12$ pulse with strong ${ }^{1} \mathrm{H}$ decoupling at a spinning rate of $15 \mathrm{kHz} .{ }^{11} \mathrm{~B}$ crosspolarization (CP) MAS experiments were performed using weak radio frequency (rf) pulse powers for the Harman-Hahn matching condition as described in the literature. ${ }^{19}$ The ${ }^{11} \mathrm{~B}$ operating frequency was $160.5 \mathrm{MHz}$, and the spectra were referenced to an external standard of $\mathrm{BF}_{3} \cdot \mathrm{O}\left(\mathrm{CH}_{2} \mathrm{CH}_{3}\right)_{2}$ at 0 ppm.

\section{RESULTS AND DISCUSSION}

3.1. In Situ SR-PXD of $\mathrm{Ca}\left(\mathrm{BH}_{4}\right)_{2}$. Figure 1 shows the in situ SR-PXD data of $\mathrm{Ca}\left(\mathrm{BH}_{4}\right)_{2}$ obtained under two different pressures $\left(p\left(\mathrm{H}_{2}\right)=10\right.$ and 20 bar $)$ together with 1 bar data that have been reported in our previous paper. ${ }^{3}$ Reactions under $p\left(\mathrm{H}_{2}\right)=1$ bar can be briefly summarized as follows: the $\beta$ $\mathrm{Ca}\left(\mathrm{BH}_{4}\right)_{2}$ signal disappears quickly in the temperature range of $323-330{ }^{\circ} \mathrm{C}$, and then at approximately $330{ }^{\circ} \mathrm{C}$, the peaks for the $\mathrm{CaB}_{2} \mathrm{H}_{x}$ phase appear. Figure 1 further shows that the $\mathrm{CaB}_{2} \mathrm{H}_{x}$ phase was the only crystalline phase detected in the temperature range of $330-335{ }^{\circ} \mathrm{C}$. The significant decrease of the XRD intensity, along with NMR data, reveals that the phase change from $\beta-\mathrm{Ca}\left(\mathrm{BH}_{4}\right)_{2}$ to $\mathrm{CaB}_{2} \mathrm{H}_{x}$ explains a small portion of the $\mathrm{Ca}\left(\mathrm{BH}_{4}\right)_{2}$ transformation, while the majority of $\beta$ $\mathrm{Ca}\left(\mathrm{BH}_{4}\right)_{2}$ becomes invisible in XRD. As shown in Figure 1c, the gradual phase transformation from $\mathrm{CaB}_{2} \mathrm{H}_{x}$ to $\mathrm{CaH}_{2}$ takes place in the range of $335-380{ }^{\circ} \mathrm{C}$. With separate confirmation of the formation of a dehydrogenation product, $\mathrm{CaB}_{6}$ by ${ }^{11} \mathrm{~B}$ $\mathrm{NMR}^{3}$ the overall reaction was formulated in reaction 2 as a possible reaction route.

The proposed reaction route was further examined by varying the hydrogen back-pressure. After the pressure is increased to $p\left(\mathrm{H}_{2}\right)=10 \mathrm{bar}$, the dehydrogenation of $\mathrm{Ca}\left(\mathrm{BH}_{4}\right)_{2}$ shifts to a higher temperature than that of $\mathrm{Ca}\left(\mathrm{BH}_{4}\right)_{2}$ under $p\left(\mathrm{H}_{2}\right)=1$ bar. The intensities of the $\mathrm{Ca}\left(\mathrm{BH}_{4}\right)_{2}$ peaks decrease rapidly, and the peaks disappear at approximately $350{ }^{\circ} \mathrm{C}$. $\mathrm{CaB}_{2} \mathrm{H}_{x}$ and $\mathrm{CaH}_{2}$ peaks appear at the same temperature of 350 ${ }^{\circ} \mathrm{C}$. The peak intensity of $\mathrm{CaB}_{2} \mathrm{H}_{x}$ is relatively small, but the entire dehydrogenation reaction routes under $p\left(\mathrm{H}_{2}\right)=10 \mathrm{bar}$ are qualitatively similar to those observed at $p\left(\mathrm{H}_{2}\right)=1$ bar. At $p\left(\mathrm{H}_{2}\right)=20$ bar, however, the $\mathrm{CaB}_{2} \mathrm{H}_{x}$ phase is not detected during the decomposition reaction, while the formation of $\mathrm{CaH}_{2}$ is still observable. When the hydrogen back-pressure is increased, the formation of $\mathrm{CaB}_{2} \mathrm{H}_{x}$ is suppressed, so it is possible to conclude that some $\mathrm{Ca}\left(\mathrm{BH}_{4}\right)_{2}$ directly decomposes into $\mathrm{CaH}_{2}$ and $\mathrm{CaB}_{6}$, as shown in reaction 1 . Noncrystalline dehydrogenation products are discussed in section 3.3.

3.2. Formation of $\mathrm{CaB}_{2} \mathrm{H}_{x}$ and $\mathrm{CaH}_{2}$. The normalized intensities of in situ SR-PXD data are shown in Figure 2. For this plot, we utilized the intensities of the strongest peak, such as the peak at $2 \theta=10^{\circ}$ for $\beta-\mathrm{Ca}\left(\mathrm{BH}_{4}\right)_{2}$, and each identified crystalline phase in the in situ SR-PXD data (Figure 1) is normalized to the intensity of the highest peak of $\beta-\mathrm{Ca}\left(\mathrm{BH}_{4}\right)_{2}$ at $317{ }^{\circ} \mathrm{C}$. The peak intensities of all other newly formed dehydrogenated species are significantly weaker than that of the starting $\mathrm{Ca}\left(\mathrm{BH}_{4}\right)_{2}$, suggesting that the majority of the dehydrogenated intermediate products are amorphous and are not detected in the in situ measurements. Nonetheless, Figure 2 allows us to extract one important piece of information: $\mathrm{CaB}_{2} \mathrm{H}_{x}$ formation is noticeable, particularly for low $\mathrm{H}_{2}$ back-pressures (see $p\left(\mathrm{H}_{2}\right)=1$ bar), and it markedly diminishes at high $\mathrm{H}_{2}$ back-pressures (barely observed under $p\left(\mathrm{H}_{2}\right)=10$ bar and not observed under $p\left(\mathrm{H}_{2}\right)=20$ bar $)$. The SR-PXD result indicates that the $\mathrm{CaB}_{2} \mathrm{H}_{x}$ phase, under a high $\mathrm{H}_{2}$ pressure, is thermodynamically unfavorable or its formation 


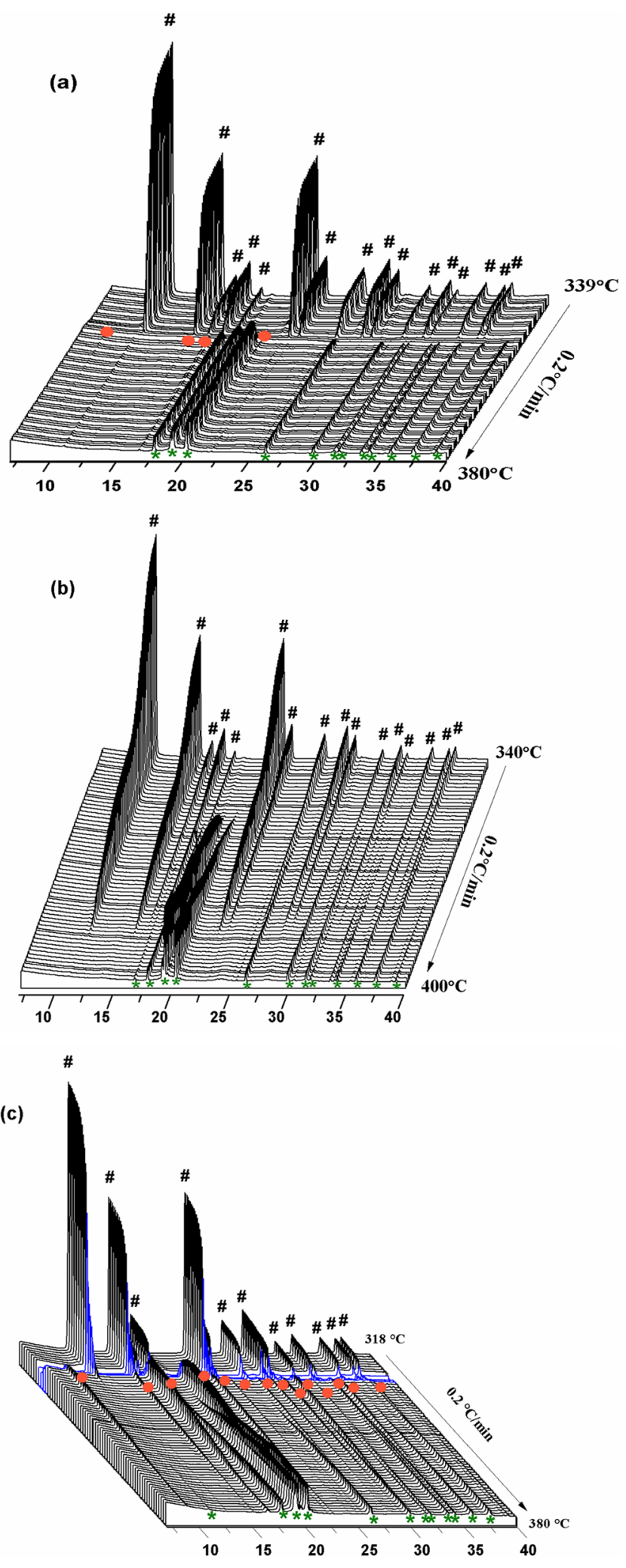

Figure 1. In situ SR-PXD of $\mathrm{Ca}\left(\mathrm{BH}_{4}\right)_{2}$ in the temperature range of $310-400{ }^{\circ} \mathrm{C}$ under two different pressures. $\beta-\mathrm{Ca}\left(\mathrm{BH}_{4}\right)_{2}$ samples dehydrogenated under (a) 10 bar of $\mathrm{H}_{2}$, (b) 20 bar of $\mathrm{H}_{2}$, and (c) 1 bar of $\mathrm{H}_{2}$. The pound signs, orange circles, and green asterisks represent $\beta$ - $\mathrm{Ca}\left(\mathrm{BH}_{4}\right)_{2}, \mathrm{CaB}_{2} \mathrm{H}_{x}$, and $\mathrm{CaH}_{2}$, respectively.

takes place in an invisible manner, such as in an amorphous phase.

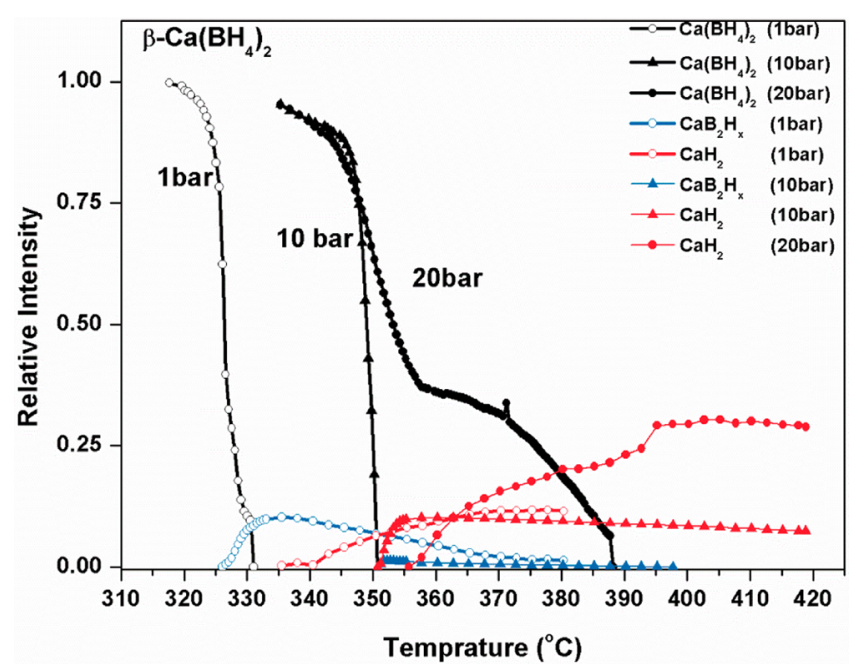

Figure 2. Normalized intensities of the in situ SR-PXD data measured for $\mathrm{Ca}\left(\mathrm{BH}_{4}\right)_{2}$ under three different pressures (see Figure 1). The open circles, triangles, and solid circles represent measurements under $p\left(\mathrm{H}_{2}\right)=1,10$, and 20 bar, respectively. Additionally, the black, blue, and red lines represent the quantities of the $\beta-\mathrm{Ca}\left(\mathrm{BH}_{4}\right)_{2}, \mathrm{CaB}_{2} \mathrm{H}_{x}$, and $\mathrm{CaH}_{2}$ phases, respectively.

$\mathrm{CaH}_{2}$ is commonly observed as a dehydrogenation reaction product, and the profile of $\mathrm{CaH}_{2}$ formation in our observation plays a valuable role in determining the reaction routes. Under $p\left(\mathrm{H}_{2}\right)=1$ bar, the $\mathrm{CaH}_{2}$ phase is formed slowly in the range of $335-380{ }^{\circ} \mathrm{C}$, which corresponds well to the slow decrease of the $\mathrm{CaB}_{2} \mathrm{H}_{x}$ phase. From this result, the following dehydrogenation route to $\mathrm{CaH}_{2}$ formation can be suggested at $p\left(\mathrm{H}_{2}\right)=1$ bar:

$$
\mathrm{CaB}_{2} \mathrm{H}_{x} \rightarrow{ }^{2} / 3 \mathrm{CaH}_{2}+1 / 3 \mathrm{CaB}_{6}+(x / 2-2 / 3) \mathrm{H}_{2}
$$

Under $p\left(\mathrm{H}_{2}\right)=10$ bar, both $\mathrm{CaH}_{2}$ and $\mathrm{CaB}_{2} \mathrm{H}_{x}$ are produced simultaneously only after the crystalline $\mathrm{Ca}\left(\mathrm{BH}_{4}\right)_{2}$ phase disappears completely at approximately $350{ }^{\circ} \mathrm{C}$. After a sudden increase in the $\mathrm{CaH}_{2}$ peak in the temperature range of 351-355 ${ }^{\circ} \mathrm{C}$, the intensity remains constant. While the intensity of $\mathrm{CaB}_{2} \mathrm{H}_{x}$ is significantly lower than that at 1 bar, the intensities of the $\mathrm{CaH}_{2}$ phase obtained under $p\left(\mathrm{H}_{2}\right)=1$ and 10 bar are similar. It is not likely that $\mathrm{CaH}_{2}$ is directly formed by the decomposition of $\beta-\mathrm{Ca}\left(\mathrm{BH}_{4}\right)_{2}$, as evidenced in the in situ SRXRD observation, but rather that $\mathrm{CaH}_{2}$ begins to appear after $\mathrm{Ca}\left(\mathrm{BH}_{4}\right)_{2}$ disappears completely. This result allows us to speculate that species in the amorphous phase should participate in the formation of $\mathrm{CaH}_{2}$. Here, we formulate the dehydrogenation reaction under $p\left(\mathrm{H}_{2}\right)=10$ bar as follows:

$$
\text { amorphous phase } \rightarrow x \mathrm{CaH}_{2}+y \mathrm{CaB}_{6}+z \mathrm{H}_{2}
$$

Under $p\left(\mathrm{H}_{2}\right)=20$ bar, Figure 2 shows that the intensity of $\mathrm{CaH}_{2}$ increases at the same rate at which the intensity of $\mathrm{Ca}\left(\mathrm{BH}_{4}\right)_{2}$ decreases, which supports reaction 1 .

In addition to the pressure effects, there could be a temperature effect because a significant difference in the $\mathrm{CaH}_{2}$ formation temperature is present depending on the increase in pressure. These results indicate that the main reaction route to the formation of $\mathrm{CaH}_{2}$ can be changed by varying the $\mathrm{H}_{2}$ back-pressure.

3.3. Formation of Amorphous Phases. All in situ XRD data show a sudden decrease in $\beta-\mathrm{Ca}\left(\mathrm{BH}_{4}\right)_{2}$ without the accompanying increase in any other Bragg peaks, suggesting 
that the solid-state chemical reaction occurs mainly in the noncrystalline, i.e., amorphous, phase. In addition to $\beta$ $\mathrm{Ca}\left(\mathrm{BH}_{4}\right)_{2}$ in the amorphous phase, other species in amorphous phases, such as $\mathrm{CaB}_{12} \mathrm{H}_{12}$ or elemental boron, are well-known as the dehydrogenation products of metal borohydrides. In the present study, we are particularly interested in confirming the formation of amorphous boron, $\mathrm{B}$, and $\mathrm{CaB}_{12} \mathrm{H}_{12}$ under various hydrogen back-pressures. We prepared four samples dehydrogenated under different hydrogen pressures. The sample dehydrogenated under $p\left(\mathrm{H}_{2}\right)=5$ bar was also included for the ex situ analysis, so samples obtained under $p\left(\mathrm{H}_{2}\right)=1,5,10$, and 20 bar were analyzed. Each sample was heated to $420{ }^{\circ} \mathrm{C}$ with a slow heating rate of $0.2{ }^{\circ} \mathrm{C} / \mathrm{min}$. As the hydrogen pressure increases, the dehydrogenation temperature of $\mathrm{Ca}$ $\left(\mathrm{BH}_{4}\right)_{2}$ increases. However, when we look over in situ XRD patterns, there are no significant differences in the final decomposition temperature (above which the XRD patterns do not change) up to 20 bar. Thus, we prepared fully dehydrogenated samples at the same temperature $\left(420{ }^{\circ} \mathrm{C}\right)$, so the result will represent the high-pressure effect on the dehydrogenation of $\mathrm{Ca}\left(\mathrm{BH}_{4}\right)_{2}$. All XRD patterns show broad humps in the background around $22^{\circ}$. The humps in each pattern come from the $\mathrm{X}$-ray scattering by the glass capillary tube. The amorphous " $\mathrm{Ca}\left(\mathrm{BH}_{4}\right)_{2}$-related" or elemental boron could also be observed, if any, in the same range as a broad halo, such as the case in $\mathrm{Mg}\left(\mathrm{BH}_{4}\right)_{2}{ }^{20}$ XRD patterns of dehydrogenated phases at $420{ }^{\circ} \mathrm{C}$ show the peaks from $\mathrm{CaH}_{2}$ and broad humps from $\mathrm{CaB}_{6}$, which are expected in the

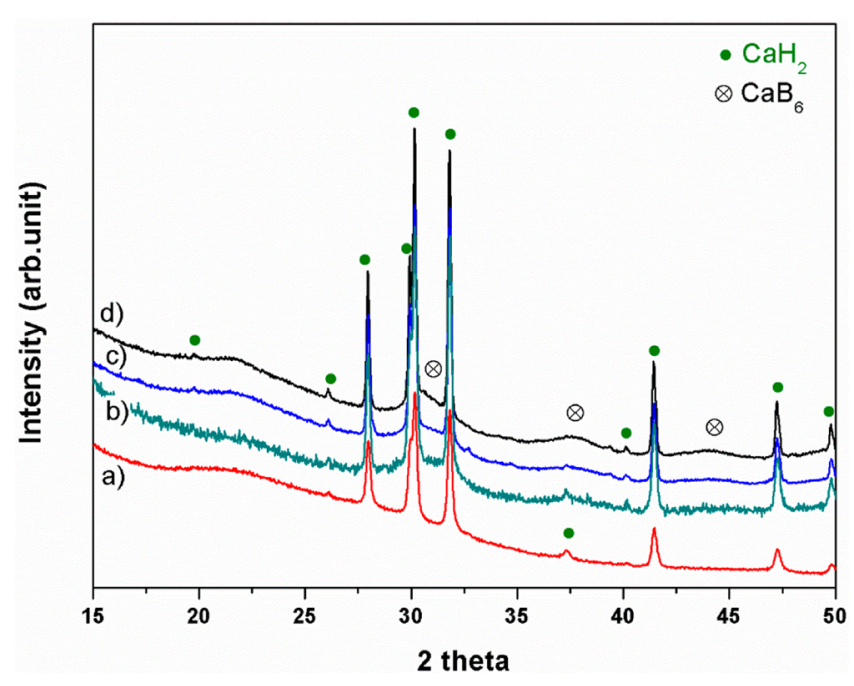

Figure 3. Ex situ XRD data of four dehydrogenated samples at $420{ }^{\circ} \mathrm{C}$ under (a) $p\left(\mathrm{H}_{2}\right)=1$ bar, (b) $p\left(\mathrm{H}_{2}\right)=5 \mathrm{bar}$, (c) $p\left(\mathrm{H}_{2}\right)=10 \mathrm{bar}$, and (d) $p\left(\mathrm{H}_{2}\right)=20$ bar.

$\mathrm{Ca}\left(\mathrm{BH}_{4}\right)_{2}$ dehydrogenation reaction (see Figure 3). In contrast, ${ }^{11} \mathrm{~B}$ NMR data further show the presence of several noncrystalline phases, as shown in Figure 4. For the sample that was dehydrogenated under $p\left(\mathrm{H}_{2}\right)=1$ bar, three broad peaks at $14,-16$, and $-30 \mathrm{ppm}$ are assigned to $\mathrm{CaB}_{6}$, $\mathrm{CaB}_{12} \mathrm{H}_{12}$, and the unidentified amorphous phase $(\mathrm{s})$, respectively. The $-30 \mathrm{ppm}$ peak appeared closer to the $\alpha-\mathrm{Ca}\left(\mathrm{BH}_{4}\right)_{2}$ peak compared to the $-31.8 \mathrm{ppm}$ peak of the amorphous phase observed at a lower decomposition temperature in our previous report. ${ }^{3}$ Because the NMR measurements here are performed ex situ and at ambient temperature, the detection of the $\alpha$ -
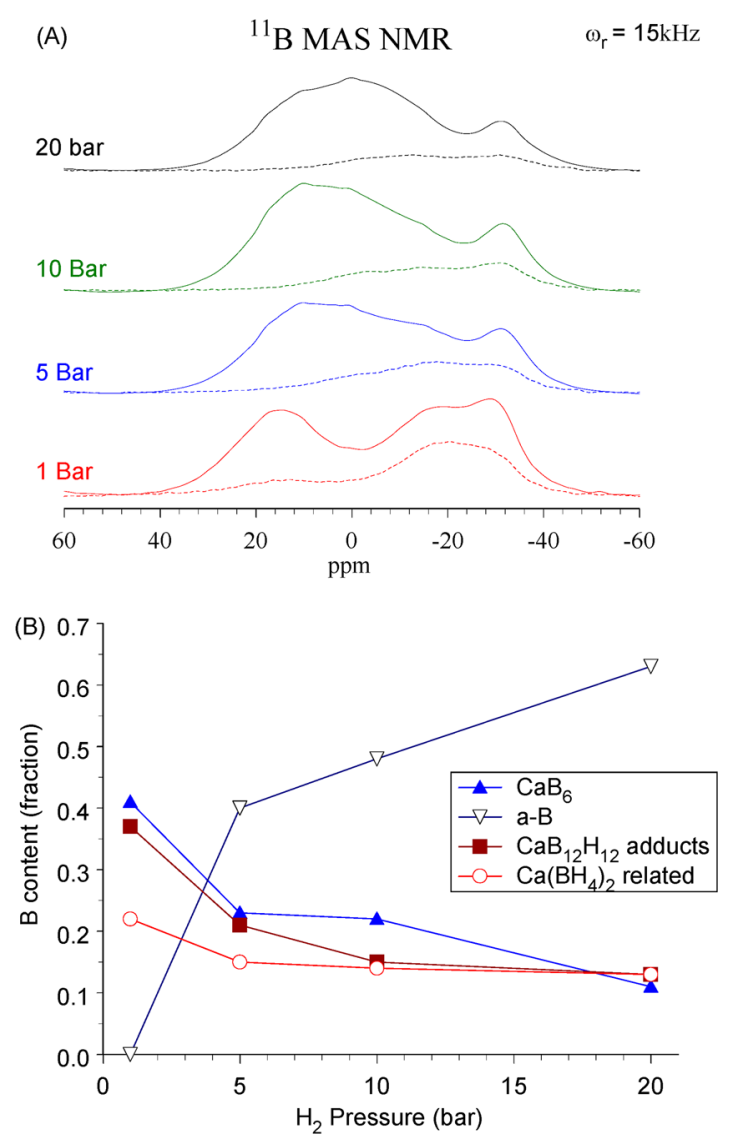

Figure 4. (A) NMR data of three dehydrogenated samples at $420{ }^{\circ} \mathrm{C}$ under (a) $p\left(\mathrm{H}_{2}\right)=1 \mathrm{bar}$, (b) $p\left(\mathrm{H}_{2}\right)=5 \mathrm{bar}$, (c) $p\left(\mathrm{H}_{2}\right)=10 \mathrm{bar}$, and (d) $p\left(\mathrm{H}_{2}\right)=20$ bar. Broken lines represent ${ }^{11} \mathrm{~B}$ CPMAS NMR spectra obtained using $0.075 \mathrm{~ms}$ of cross-polarization contact time. (B) Relative composition of boron species obtained from the spectral decomposition of ${ }^{11} \mathrm{~B}$ spectra in (A) as a function of the hydrogen back-pressure in the thermal decomposition of $\mathrm{Ca}\left(\mathrm{BH}_{4}\right)_{2}$.

$\mathrm{Ca}\left(\mathrm{BH}_{4}\right)_{2}$ phase after cooling is understandable. However, it is still not settled whether the peak represents unreacted $\alpha$ $\mathrm{Ca}\left(\mathrm{BH}_{4}\right)_{2}$ in a highly disordered environment due to the broadening and lack of spinning sidebands, which make it difficult to access the structural information. As shown above, the XRD data do not support the existence of a $\mathrm{Ca}\left(\mathrm{BH}_{4}\right)_{2}$ phase. Therefore, we leave the peak unassigned as the "unidentified amorphous phase(s)" observed at the initial dehydrogenation step of $\mathrm{Ca}\left(\mathrm{BH}_{4}\right)_{2} .{ }^{11} \mathrm{~B} \mathrm{CP}$ MAS experiments were performed for these samples and plotted together in a broken line as shown in Figure 4. The $-30 \mathrm{ppm}$ peak always appears in the CP spectra (with a cross-polarization contact time of $0.075 \mathrm{~ms}$ ), so from this further characterization it is concluded that the $-30 \mathrm{ppm}$ peak is a boron species with $\mathrm{B}-\mathrm{H}$ bonds. Three peaks corresponding to $\mathrm{CaB}_{6}, \mathrm{CaB}_{12} \mathrm{H}_{12}$, and the unidentified amorphous phase are also observed in the samples dehydrogenated under $p\left(\mathrm{H}_{2}\right)=5,10$, and 20 bar. However, elemental boron is now observed on the basis of the broad peaks at $\sim 4.5$ and $16 \mathrm{ppm}$ (see Figure S1, Supporting Information), implying that one of the dehydrogenation products under high $\mathrm{H}_{2}$ pressures is an amorphous form of elemental boron. ${ }^{17,18}$ By applying a high hydrogen pressure, not only the suppression of $\mathrm{CaB}_{12} \mathrm{H}_{12}$ but also a decrease in $\mathrm{CaB}_{6}$ and an increase in elemental boron are observed. Note that, in the ${ }^{11} \mathrm{~B}$ MAS NMR spectra of these samples, the elemental 
boron peak appears featurelessly overlapped with the $\mathrm{CaB}_{6}$ signal at $14 \mathrm{ppm}$ and with $\mathrm{CaB}_{12} \mathrm{H}_{12}$ at $\sim-16 \mathrm{ppm}$. For example, according to ${ }^{11} \mathrm{~B} \mathrm{CP}$ MAS spectra shown in Figure 4, the major part of the signal at around $-16 \mathrm{ppm}$ (for samples under high $\mathrm{H}_{2}$ pressure) is a boron species without $\mathrm{B}-\mathrm{H}$ bonds. The result further supports the presence of amorphous elemental boron. In our best effort, the presence of broad resonances at 4.5 and $-16 \mathrm{ppm}$ for three samples was analyzed by spectral decomposition (see Figure S2, Supporting Information; the method was used in the previous arusy on the $\mathrm{LiBH}_{4}$ decomposition reaction under various $\mathrm{H}_{2}$ backpressures ${ }^{17}$ ). For this process, the ${ }^{11} \mathrm{~B}$ MAS NMR spectrum of amorphous B (Sigma-Aldrich) and its decomposition (see Figure S1) were closely utilized. The same line widths and the intensity ratio between the two peaks were employed in all the decomposition attempts to draw a reasonable spectral fit. The intensity of the $4 \mathrm{ppm}$ peak was first estimated, and the -16 ppm peak was artificially added with the corresponding intensity ratio. The rest of the signal was filled with addition of the $\mathrm{CaB}_{12} \mathrm{H}_{12}$ peak. Therefore, the quantitation of $\mathrm{CaB}_{12} \mathrm{H}_{12}$ is believed to be particularly inaccurate. In addition, note that the spectral decomposition was performed on the center bands of the central transition of ${ }^{11} \mathrm{~B}(I=3 / 2)$ MAS spectra that were acquired with a small nutation angle. Due to the highly disordered environment of the boron species in this case, no MAS NMR powder line shape is well-defined. ${ }^{19}$ Consequently, the center band peaks are expected to contribute to the spinning sidebands originating from the satellite transition of ${ }^{11} \mathrm{~B}$ nuclei, which are nearly impossible to resolve and can be an additional inaccuracy in the boron quantitation. ${ }^{21,22}$ Because all boron peaks behave in the same manner and there is no wellestablished method for handling the complexity, we ignored the satellite transitions in the calculation. Nonetheless, the amount of elemental boron species was quantified along with other boron species, and the result is shown in Figure 4B as a function of the hydrogen back-pressure. In the plot, it is easy to see how quickly the formation of elemental boron increases with increasing $\mathrm{H}_{2}$ back-pressure. Smaller amounts of $\mathrm{CaB}_{6}$ and $\mathrm{CaB}_{12} \mathrm{H}_{12}$ species were formed, while they showed a different behavior at high pressures. Note here that the peaks at -32 and $-41 \mathrm{ppm}$ (see Figure $\mathrm{S} 1$ ) were labeled as " $\mathrm{Ca}\left(\mathrm{BH}_{4}\right)_{2}$-related," which corresponds to the "unidentified amorphous phase(s)" mentioned above. Such intermediate species showed a minor decrease under $p\left(\mathrm{H}_{2}\right)=5$ bar and remained unchanged at the higher pressures.

While the elemental boron formation and its amount of change under different $\mathrm{H}_{2}$ back-pressures are now better understood as a result of the ${ }^{11} \mathrm{~B}$ NMR study, it is not yet clear which reaction pathway is operating. However, the following dehydrogenation reaction can be formulated as a separate path under $p\left(\mathrm{H}_{2}\right)=5,10$, and 20 bar:

$$
\mathrm{Ca}\left(\mathrm{BH}_{4}\right)_{2} \rightarrow \mathrm{CaH}_{2}+2 \mathrm{~B}+3 \mathrm{H}_{2}
$$

In our previous study, ${ }^{4}$ DFT calculations predicted that the enthalpies of reactions 1 and 6 were 40.6 and $57.3 \mathrm{~kJ} / \mathrm{mol}$ of $\mathrm{H}_{2}$, respectively. On the basis of these results, we plotted the van't Hoff curves in Figure 5, which indicate that reaction 1 is more favorable than reaction 6 under our experimental pressures. However, even with the favorable thermodynamics of reaction 1, the $\mathrm{Ca}\left(\mathrm{BH}_{4}\right)_{2}$ residue was found; in other words, the reaction was not completed. The ${ }^{11} \mathrm{~B}$ NMR data (Figure 4) support the existence of a $\mathrm{Ca}\left(\mathrm{BH}_{4}\right)_{2}$-related amorphous phase, and this phase remains, even at the higher temperature of 500

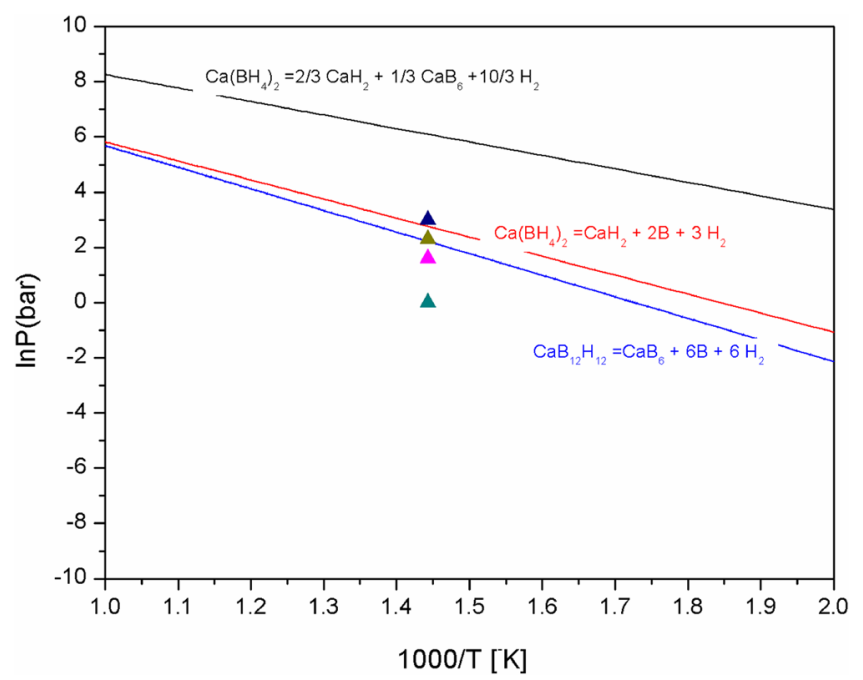

Figure 5. van't Hoff curves of reactions 1, 6, and 7. Each thermodynamic value is obtained from a previously reported paper. ${ }^{4,23}$ The experimental conditions required to obtain the dehydrogenated samples are marked with triangles. The dehydrogenation temperature of all samples is $420{ }^{\circ} \mathrm{C}$. Green, pink, yellow, and blue triangles represent the dehydrogenation under $p\left(\mathrm{H}_{2}\right)=1,5,10$, and 20 bar, respectively.

${ }^{\circ} \mathrm{C} .{ }^{3}$ This evidence of the $\mathrm{Ca}\left(\mathrm{BH}_{4}\right)_{2}$ residue might indicate slow kinetics for reaction 1 . It is still ambiguous why crystalline $\mathrm{Ca}\left(\mathrm{BH}_{4}\right)_{2}$ transforms into an amorphous form during heating and why it decomposes very slowly. However, we can speculate that the slow kinetics provide room for the thermodynamically less favorable reaction 6 to occur.

Elemental boron can also be formed from the dehydrogenation of amorphous $\mathrm{CaB}_{12} \mathrm{H}_{12}$ :

$$
\mathrm{CaB}_{12} \mathrm{H}_{12} \rightarrow \mathrm{CaB}_{6}+6 \mathrm{~B}+6 \mathrm{H}_{2}
$$

The enthalpy and entropy change of reaction 7 is $73.7 \mathrm{~kJ} / \mathrm{mol}$ of $\mathrm{H}_{2}$ and $127.4 \mathrm{~J} /\left(\mathrm{K}\right.$ mol of $\left.\mathrm{H}_{2}\right){ }^{23}$ respectively, which predicted reaction 7 can occur at $420{ }^{\circ} \mathrm{C}$ under $p\left(\mathrm{H}_{2}\right)=5$ bar. Reaction 7 becomes thermodynamically unfavorable as $p\left(\mathrm{H}_{2}\right)$ increases above 10 bar. Furthermore, it is experimentally observed that the presence of $\mathrm{CaH}_{2}$ promotes the dehydrogenation of $\mathrm{CaB}_{12} \mathrm{H}_{12}$ through reaction 8 instead of reaction $7:^{8}$

$$
\mathrm{CaB}_{12} \mathrm{H}_{12}+\mathrm{CaH}_{2} \rightarrow 2 \mathrm{CaB}_{6}+7 \mathrm{H}_{2}
$$

Therefore, we can predict that reactions 7 and 8 are not the main routes to form elemental boron.

The reasons for the formation of elemental boron are not clear at this point, but on the basis of the above results, there appears to be a subtle competition among different dehydrogenation reaction paths, depending on the hydrogen back-pressure and temperature. A high hydrogen back-pressure promotes the formation of a stable compound, such as elemental boron, which is not a desirable dehydrogenation route with respect to reversibility. As discussed above, the kinetics of the $\mathrm{Ca}\left(\mathrm{BH}_{4}\right)_{2}$-related amorphous phase appear to play a very important role in the reversible formation of $\mathrm{Ca}\left(\mathrm{BH}_{4}\right)_{2}$. Among the intermediate phases, $\mathrm{CaB}_{2} \mathrm{H}_{x}$ is fully reversible under relatively moderate conditions without any catalytic additive. ${ }^{3}$ With a catalytic additive, $\mathrm{CaH}_{2}$ can be rehydrogenated by the reaction with $\mathrm{CaB}_{6}{ }^{24}$ or $\mathrm{MgB}_{2}{ }^{25}$ under moderate conditions. However, the formation of $\mathrm{CaB}_{12} \mathrm{H}_{12}$ and elemental boron as final products could lead to a degradation in 
the reversibility of the dehydrogenation reaction because of their high stabilities. To avoid the formation of unwanted $\mathrm{CaB}_{12} \mathrm{H}_{12}$ or elemental boron, control of the dehydrogenation reaction pathway is crucial for reversible hydrogen storage. The exact dehydrogenation reaction route and method of controlling the reaction path of $\mathrm{Ca}\left(\mathrm{BH}_{4}\right)_{2}$ must be further explored to make $\mathrm{Ca}\left(\mathrm{BH}_{4}\right)_{2}$ more reversible under mild conditions for practical applications.

\section{CONCLUSIONS}

We attempted to control the reaction pathway of $\mathrm{Ca}\left(\mathrm{BH}_{4}\right)_{2}$ by applying different hydrogen back-pressures. $\mathrm{Ca}\left(\mathrm{BH}_{4}\right)_{2}$ decomposes when heated to $420{ }^{\circ} \mathrm{C}$ to form an unidentified amorphous phase(s), $\mathrm{CaB}_{2} \mathrm{H}_{x}, \mathrm{CaB}_{12} \mathrm{H}_{12}, \mathrm{CaH}_{2}, \mathrm{CaB}_{6}$, and elemental boron. Several reactions that form dehydrogenated phases occur almost simultaneously over a wide temperature range, which makes it difficult to formulate the dehydrogenation reactions in sequential order. Under $p\left(\mathrm{H}_{2}\right)=1$ bar, among the dehydrogenation products, elemental boron is not observed during heating. When the hydrogen back-pressure increases, the formation of $\mathrm{CaB}_{2} \mathrm{H}_{x}$ decreases but the formation of elemental boron increases. For kinetic reasons, there is subtle competition among the different reaction pathways, and we found that they are strongly affected by the hydrogen backpressure. Our results indicate that the dehydrogenation kinetics of the $\mathrm{Ca}\left(\mathrm{BH}_{4}\right)_{2}$-related amorphous phase play a very important role in controlling the compositions of the final dehydrogenation products, which in turn control the reversibility of the $\mathrm{Ca}\left(\mathrm{BH}_{4}\right)_{2}$ reaction. By applying suitable dehydrogenation conditions (hydrogen back-pressure and temperature), the dehydrogenation reaction pathway can be selected.

\section{ASSOCIATED CONTENT}

\section{(S Supporting Information}

${ }^{11} \mathrm{~B}$ MAS NMR spectrum of amorphous boron and its decomposition into two major peaks at 4.5 and $-16 \mathrm{ppm}$ and ${ }^{11} \mathrm{~B}$ MAS NMR spectra showing decomposition into $\mathrm{CaB}_{6}$, elemental boron, $\mathrm{CaB}_{12} \mathrm{H}_{12}$, and the $\mathrm{Ca}\left(\mathrm{BH}_{4}\right)_{2}$-related unidentified amorphous phase. This material is available free of charge via the Internet at http://pubs.acs.org.

\section{AUTHOR INFORMATION}

\section{Corresponding Author}

*E-mail: oze@kist.re.kr.

\section{Notes}

The authors declare no competing financial interest.

\section{ACKNOWLEDGMENTS}

This work was sponsored by the Korea Research Council of Fundamental Science and Technology via a joint research project. We thank Drs. Keun Hwa Chae and Ik Jae Lee of PAL for the in situ synchrotron XRD measurements. The NMR facility at Caltech is supported by the National Science Foundation (NSF) under Grant No. 9724240 and partially supported by the MRSEC Program of the NSF under Award No. DMR-520565. H.N.H. and Y.K. acknowledge support by the Converging Research Center Program (Grant No. 2011K000599) through the Ministry of Education, Science and Technology of the Korean Government.

\section{REFERENCES}

(1) Buchter, F.; Lodziana, Z.; Remhof, A.; Friedrichs, O.; Borgschulte, A.; Mauron, P.; Zuttel, A.; Sheptyakov, D.; Barkhordarian, G.; Bormann, R. d.; et al. J. Phys. Chem. B 2008, $112,8042$.

(2) Kim, J.-H.; Jin, S.-A.; Shim, J.-H.; Cho, Y. W. J. Alloys Compd. 2008, 461, L20.

(3) Kim, Y.; Hwang, S.-J.; Shim, J.-H.; Lee, Y.-S.; Han, H. N.; Cho, Y. W. J. Phys. Chem. C 2012, 116, 4330.

(4) Kim, Y.; Reed, D.; Lee, Y.-S.; Lee, J. Y.; Shim, J.-H.; Book, D.; Cho, Y. W. J. Phys. Chem. C 2009, 113, 5865.

(5) Lee, J. Y.; Ravnsbak, D.; Lee, Y.-S.; Kim, Y.; Cerenius, Y.; Shim, J.-H.; Jensen, T. R.; Hur, N. H.; Cho, Y. W. J. Phys. Chem. C 2009, 113, 15080 .

(6) Riktor, M. D.; Sørby, M. H.; Chłopek, K.; Fichtner, M.; Hauback, B. C. J. Mater. Chem. 2009, 19, 2754.

(7) Kulkarni, A. D.; Wang, L.-L.; Johnson, D. D.; Sholl, D. S.; Johnson, J. K. J. Phys. Chem. C 2010, 114, 14601.

(8) Stavila, V.; Her, J.-H.; Zhou, W.; Hwang, S.-J.; Kim, C.; Ottley, L. A. M.; Udovic, T. J. J. Solid State Chem. 2010, 183, 1133.

(9) Wang, L.-L.; Graham, D. D.; Robertson, I. M.; Johnson, D. D. J. Phys. Chem. C 2009, 113, 20088.

(10) Bonatto Minella, C.; Garroni, S.; Pistidda, C.; Gosalawit-Utke, R.; Barkhordarian, G.; Rongeat, C.; Lindemann, I.; Gutfleisch, O.; Jensen, T. R.; Cerenius, Y.; et al. J. Phys. Chem. C 2011, 115, 2497.

(11) Aoki, M.; Miwa, K.; Noritake, T.; Ohba, N.; Matsumoto, M.; Li, H. W.; Nakamori, Y.; Towata, S.; Orimo, S. Appl. Phys. A: Mater. Sci. Process. 2008, 92, 601.

(12) Riktor, M. D.; Sørby, M. H.; Chłopek, K.; Fichtner, M.; Buchter, F.; Züttel, A.; Hauback, B. C. J. Mater. Chem. 2007, 17, 4939.

(13) Ronnebro E., M. E. DOE Hydrogen Program and Annual Peer Review Meeting Proceedings; U.S. Department of Energy: Washington, DC, 2008; Project ID ST36.

(14) Chong, M.; Karkamkar, A.; Autrey, T.; Orimo, S.-i.; Jalisatgi, S.; Jensen, C. M. Chem. Commun. 2011, 47, 1330.

(15) Jae-Hyeok Shim, J.-H. L.; Rather, S.-u.; Lee, Y.-S.; Reed, D.; Kim, Y.; Book, D.; Cho, Y. W. J. Phys. Chem. Lett. 2010, 1, 59.

(16) Kim, K. B.; Shim, J. H.; Cho, Y. W.; Oh, K. H. Chem. Commun. 2011, 47, 9831 .

(17) Noth, H. Z. Naturforsch., B: J. Chem. Sci. 1982, 37, 1499.

(18) Schiavo, B.; Girella, A.; Agresti, F.; Capurso, G.; Milanese, C. J. Alloys Compd. 2011, 509, S714.

(19) Hwang, S. J.; Bowman, R. C.; Reiter, J. W.; Rijssenbeek, J.; Soloveichik, G. L.; Zhao, J. C.; Kabbour, H.; Ahn, C. C. J. Phys. Chem. C 2008, 112, 3164

(20) Yaroslav Filinchuk, B. R.; Jensen, T. R.; Dmitriev, V.; Chernyshov, D.; Hagemann, H. Angew. Chem., Int. Ed. 2011, 50, 11162.

(21) E.Ashbrook, S. Phys. Chem. Chem. Phys. 2009, 11, 6892.

(22) Sott Kroeker, P. S. N.; Stebbins, J. F. J. Non-Cryst. Solids 2001, 293-295, 440.

(23) Ozolinšs, V.; Majzoub, E. H.; Wolverton, C. J. Am. Chem. Soc. 2009, 131, 230.

(24) Rönnebro, E.; Majzoub, E. H. J. Phys. Chem. B 2007, 111, 12047.

(25) Barkhordarian, B.; Jensen, T. R.; Doppiu, S.; Bösenberg, U.; Borgschulte, A.; Gremaud, R.; Cerenius, Y.; Dornheim, M.; Klassen, T.; Bormann, R. J. Phys. Chem. C 2008, 112, 2743. 